Check for updates

Cite this: RSC Adv., 2018, 8, 25754

Received 6th June 2018 Accepted 12th July 2018

DOI: $10.1039 / c 8 r a 04825 h$

rsc.li/rsc-advances

\section{Three-dimensional mesoporous calcium carbonate-silica frameworks thermally activated from porous fossil bryophyte: adsorption studies for heavy metal uptake}

\begin{abstract}
Wenlei Wang, (D)* Ren He, Tianli Yang, Yunchu Hu, Ning Zhang and Can Yang
In this paper, three-dimensional mesoporous calcium carbonate-silica frameworks have been created from the straw tufa (ST) originating from porous fossil bryophyte by a thermal activation technique. A batch of adsorption kinetic and thermodynamic experiments were used to investigate the adsorption capacity of $\mathrm{Cd}(॥)$ onto the samples. The ST after thermal activation has shown a significant ability for the uptake of heavy metals. It exhibited maximum adsorption capacities of $12.76 \mathrm{mg} \mathrm{g}^{-1}, 14.09 \mathrm{mg} \mathrm{g}^{-1}, 17.00 \mathrm{mg} \mathrm{g}^{-1}$, and $33.81 \mathrm{mg} \mathrm{g}^{-1}$ for $\mathrm{Cd}\left(\right.$ II) at the activation temperature of $300,450,600$ and $750{ }^{\circ} \mathrm{C}$, respectively. Through competitive adsorption for $\mathrm{Cd}(\|)$ and $\mathrm{Pb}(\|)$, the $\mathrm{ST}$ thermally activated at $750{ }^{\circ} \mathrm{C}$ exhibited maximum equilibrium adsorption capacities of $24.65 \mathrm{mg} \mathrm{g}^{-1}, 25.91 \mathrm{mg} \mathrm{g}^{-1}$, and $30.94 \mathrm{mg} \mathrm{g}^{-1}$ for $\mathrm{Cd}(॥)$ uptake at $298.1 \mathrm{~K}, 308.1 \mathrm{~K}$ and $318.1 \mathrm{~K}$, respectively, whereas it exhibited values of $91.59 \mathrm{mg} \mathrm{g}^{-1}, 101.32 \mathrm{mg} \mathrm{g}^{-1}$, and $112.19 \mathrm{mg} \mathrm{g}^{-1}$ for $\mathrm{Pb}(॥)$ removal. The adsorption capacities of $\mathrm{Cd}(\|)$ and $\mathrm{Pb}(\|)$ both decrease with the addition of the other heavy metal cations, indicating that the adsorption is hindered by the competitive adsorption and the adsorption active sites on the mineral surface are readily exchangeable. The adsorption of $\mathrm{Cd}(\|)$ and $\mathrm{Pb}(\|)$ followed the pseudo-second order kinetics model well. In addition, the Langmuir model could accurately describe the adsorption isotherms. Based on the results of characterization with TEM, XRD and XPS, the adsorption mechanisms could be primarily explained as formation of $\mathrm{Cd}(\mathrm{OH})_{2}$ and $\mathrm{CdCO}_{3}$ as well as $\mathrm{Cd}\left(\mathrm{HCO}_{3}\right)_{2}$ precipitation on the surface of ST. These characteristics of ion-exchange and the adsorptive property for ST modified allow it to be widely used in artificial wetland landfill and environmental protection.
\end{abstract}

\section{Introduction}

Though emissions of heavy metals into water and soil ecosystems have declined in most countries over the last decades, the danger of heavy metals to health continues and is even increasing in some parts of the world because products containing heavy metals are rarely recycled and are dumped together with household waste without any treatment. ${ }^{1-3}$ The main threats to human health from heavy metals are associated with exposure to $\mathrm{Cd}(\mathrm{II})$ and $\mathrm{Pb}(\mathrm{II}){ }^{4-7}$ Several typical techniques have been applied for heavy metal removal from aqueous solutions to minimize the risk of adverse health effects, such as hydroxide precipitation method, ${ }^{8-10}$ ferrite reaction separation, ${ }^{11}$ ion exchange method, ${ }^{12-15}$ and membrane treatment technology. ${ }^{16-19}$ Among these options, increasing attention has been paid to adsorption due to its economic feasibility, effectiveness, simplicity of application, and environmental friendliness. ${ }^{20-25}$ The adsorbent was the key parameter for the adsorption process of heavy metals. ${ }^{26,27}$ Carbonates, common

College of Science, Central South University of Forestry and Technology, Changsha 410004, P. R. China. E-mail: wenlei_wang@hotmail.com minerals in soils and sediments, show a significant ability for the uptake of divalent metals..$^{28,29}$ In addition to the low-cost adsorbents, materials such as zeolites, activated carbons, clays and biochars were used for heavy metal removal. ${ }^{30-32}$ Especially, natural minerals with mesoporous structures may have more potential to be applied in the treatment of heavy metals. ${ }^{33-35}$ Straw tufa (ST) is abundant and is essentially fossilized calcium carbonate bryophyte formed approximately 130 million to 190 million years ago. Most structures have unique porous characteristics with tubular and hollow features. The tubes are gradually formed by continuous corrosion and alternations in the process of generation due to the features of fossilized plant matter, such as stems, leaves, weeds, etc. It has great potential to be applied in the treatment of heavy metals of $\mathrm{Cd}(\mathrm{II})$ and $\mathrm{Pb}(\mathrm{II})$ in the environment.

In this paper, Brunauer-Emmett-Teller (BET) and thermogravimetric analysis-differential scanning calorimetry (TGDSC) were applied to determine the mesoporous feature and decomposition temperature on the natural carbonate ore of ST. A thermal activation is applied to modify the structural characteristics and get optimal adsorption activity of the adsorbent sample. The structural properties of the ST samples after 
thermal activation are characterized by Fourier transform infrared spectroscopy (FT-IR), X-ray diffraction (XRD), and scanning electron microscope (SEM). Then, the efficiency of ST before and after thermal activation for the uptake of $\mathrm{Cd}(\mathrm{II})$ and $\mathrm{Pb}$ (II) was systematically investigated. Based on the newly obtained experimental data of the adsorption kinetics, several kinetic models were applied to evaluate the interaction of heavy metal cations of $\mathrm{Cd}(\mathrm{II})$ and $\mathrm{Pb}$ (II) with $\mathrm{ST}$ as an adsorbent. Additionally, Langmuir and Freundlich models were used to evaluate the experimental data of the adsorption isotherms to help understand the adsorption mechanism. The adsorption mechanism of Cd(II) onto the ST sample was studied by using XRD, Transmission electron microscopy (TEM), and X-ray photoelectron spectroscopy (XPS). The results of this work will help to understand the adsorption properties of the ST on in situ curing and removal of cadmium ions as well as other heavy metal ions.

\section{Materials and methods}

\subsection{Materials and chemical regents}

The natural porous material of ST was obtained from Linqu County, Shandong province, China. All reagents $\left(\mathrm{Cd}\left(\mathrm{NO}_{3}\right)_{2}-\right.$ $\cdot 4 \mathrm{H}_{2} \mathrm{O}$ and $\mathrm{Pb}(\mathrm{NO})_{2}$ ) used in this work were analytical grade chemicals purchased from Sinopharm Chemical Reagent Co., Ltd, China. Then, $\mathrm{Cd}\left(\mathrm{NO}_{3}\right)_{2}$ and $\mathrm{Pb}\left(\mathrm{NO}_{3}\right)_{2}$ were purified two times by crystallization with half salt recovery of the analytical grade reagent in each case, as discussed in our previous work. ${ }^{36}$ The $\mathrm{Cd}(\mathrm{II})$ and $\mathrm{Pb}$ (II) stock aqueous solutions were prepared with the newly obtained chemical agents mentioned above. Doubly distilled water with $S<1.5 \times 10^{-4} \mathrm{~S} \mathrm{~m}^{-1}$ was used in the adsorption experiment. A thermostat (Lauda E219, Germany) with a temperature stability up to $\pm 0.01 \mathrm{~K}$ was used to perform the kinetic and equilibrium experiments with the bath temperature determined by a calibrated glass thermometer (Miller \& Weber, Inc., USA). The $\mathrm{Cd}(\mathrm{II})$ and $\mathrm{Pb}$ (II) analyses were performed by the standard addition method with an inductively coupled plasma optical emission spectrometer (ICP-OES) (5300DV, Perkin-Elmer, USA).

\subsection{Physical and chemical properties of the sample}

The composition of ST was evaluated by X-ray fluorescence (XRF) (PANalytical-Axios). To measure the textural properties of the sample, including the surface area, pore volume, and average pore diameter, $\mathrm{N}_{2}$ adsorption-desorption isotherms were performed on a Coulter Omnisorp 100CX BrunauerEmmett-Teller (BET) system. Simultaneous thermogravimetric (TG) and differential scanning calorimetric (DSC) measurements, TG-DSC was performed using a Netzsch STA 449C Jupiter system. Samples of approximately $200 \mathrm{mg}$ were determined from 20 to $900{ }^{\circ} \mathrm{C}$. The functional groups on the sample surface were characterized with Fourier transform infrared spectrometry (FT-IR) (Thermo Scientific Nicolet-iS10, USA) by the $\mathrm{KBr}$ pressed disk technique. The FT-IR spectrum was recorded at 32 scans per spectrum with a resolution of $0.1 \mathrm{~cm}^{-1}$ from wave numbers $400-4000 \mathrm{~cm}^{-1}$. The ratio of sorbent to $\mathrm{KBr}$ was $0.5: 100$. XRD patterns were collected on a Bruker D8 Advanced X-ray diffractometer with $\mathrm{Cu} \mathrm{K} \alpha$ radiation at $40 \mathrm{kV}$ and $40 \mathrm{~mA}$. The adsorbent was scanned with a speed of $5^{\circ}$ per min over a scanning range of $10-90^{\circ}$. Measurements on high-resolution SEM/EDS systems equipped with a transmission model for imaging and measurement of the morphology of the samples were performed on a field emission scanning electron microscope (FE-SEM) (Ultra 55, Germany). In order to investigate the adsorption mechanism onto the ST before and after adsorption, the microstructure and the element distribution of the absorbent material was analyzed by the transmission electron microscope (HR-TEM) (Tecnai G2 F20 S-TWIN). X-ray photoelectron spectroscopy (XPS) analyses were performed with an Axis Ultra spectrometer (Kratos Analytical Ltd.) using Al monochromatic X-ray source ( $\mathrm{Al} \mathrm{K} \alpha=1486.6 \mathrm{eV})$ at $25{ }^{\circ} \mathrm{C}$ in a high vacuum environment (approximately $5 \times 10^{-9}$ torr) with the binding energies calibrated with containment carbon the C $1 \mathrm{~s}(284.8 \mathrm{eV})$.

\subsection{Thermal activation}

In order to modify the characteristic properties and increase the specific surface area of ST, the ST needs to be treated by using a thermal activation technique. Preparation of threedimensional mesoporous calcium carbonate-silica frameworks was performed from a step of slow pyrogenic decomposition followed by physical activation with $\mathrm{CO}_{2}$. Amounts of $2.0 \mathrm{~g}$ of the precursor material was introduced into a stainless steel reactor with a volume of $20 \mathrm{~mL}$ and removable lid with orifices for gas inlet, which was heated in a vacuum tube furnace (KJ-T1400-L6008LB2, China) with a temperature program of three stages. The very beginning, the sample was heated with a heating rage of $30{ }^{\circ} \mathrm{C} \mathrm{min}-1$ to a prescribed temperature such as $300,450,600$ and $750{ }^{\circ} \mathrm{C}$, and then was held the prescribed temperature for $1 \mathrm{~h}$ under $\mathrm{N}_{2}$ flow of 100 $\mathrm{mL} \min ^{-1}$. Then, the temperature was increased to a aimed temperature and maintained for $2 \mathrm{~h}$. Afterwards, the crucible with the sample was removed from the vacuum tube furnace when it dropped to room temperature. Ultimately, the thermal activated ST was obtained and abbreviated as ST- $T$, where the $T$ was the above prescribed temperature.

\subsection{Batch adsorption experiments}

Cd(II) was selected as representative pollutants to investigate the adsorption properties of the thermal activated ST. A batch of experiments have been carried out on adsorption kinetics and adsorption thermodynamics. Cd(II) adsorption kinetics experiments were evaluated with $50 \mathrm{~mL}$ of $150 \mathrm{mg} \mathrm{L}^{-1} \mathrm{Cd}^{2+}$ solution in a $150 \mathrm{~mL}$ Erlenmeyer flask at $298.1 \mathrm{~K}$. The Erlenmeyer flask was shaken on a thermostat shaker (Lauda E219, Germany) under $150 \mathrm{rpm} \mathrm{min}^{-1}$. The experiments with $0.2 \mathrm{~g}$ adsorbent including ST and ST-750 were used for performing the adsorption kinetic. Samples were withdrawn from the flask at predetermined time intervals and immediately filtered by 0.45 $\mu \mathrm{m}$ membrane filters prior to further analysis. Then, the $\mathrm{Cd}(\mathrm{II})$ concentration of the samples was measured by ICP-OES. Then, adsorption isotherms of $\mathrm{Cd}(\mathrm{II})$ were carried out by a batch of 
equilibration experiments. To evaluate the influences of initial Cd(II) concentration and the thermal activation temperature, the adsorption equilibrium experiments were carried out in a $150 \mathrm{~mL}$ Erlenmeyer flask containing $50 \mathrm{~mL}$ of Cd(II) aqueous solution $\left(50,100,150\right.$, and $\left.200 \mathrm{mg} \mathrm{L}^{-1}\right)$ and $0.2 \mathrm{~g}$ adsorbents including ST, ST-300, ST-450, ST-600, and ST-750. The Erlenmeyer flasks were shaken for $12 \mathrm{~h}$ in a thermostat at $298.1 \mathrm{~K}$ with temperature stability up to $\pm 0.1 \mathrm{~K}$. The $\mathrm{pH}$ value of the reaction solution was maintained at 6 for subsequent adsorption experiments. The supernatants were collected to determine the equilibrium $\mathrm{Cd}(\mathrm{II})$ concentrations by a syringe with $0.45 \mu \mathrm{m}$ membrane filters.

The competitive adsorption experiments in contact with $\mathrm{Cd}$ (II) and $\mathrm{Pb}$ (II) were conducted in controlled aqueous systems. $50 \mathrm{~mL}$ of $\mathrm{Cd}$ (II) and $\mathrm{Pb}(\mathrm{II})$ stock aqueous solutions were transferred into a ground $150 \mathrm{~cm}^{3}$ Erlenmeyer flask at $T=298.1$, 308.1 and $318.1 \mathrm{~K}$. The content of the aqueous solution was set to a standard value by diluting the above stock solutions. Then, $0.2 \mathrm{~g}$ of ST-750 was added as an adsorbent to the reaction aqueous solution. The adsorption sample was placed into a glycol-water bath thermostat and stirred by a magnetic stirrer at $150 \mathrm{rpm}$ outside the bath. The adsorption kinetics experiments were conducted at predetermined times of 5, 15, 30, 45, $60,90,120,300,720,900$, and $1440 \mathrm{~min}$ with the initial Cd(II) and $\mathrm{Pb}$ (II) concentrations set at $100 \mathrm{mg} \mathrm{L}^{-1}$ and $400 \mathrm{mg} \mathrm{L}^{-1}$, respectively. The adsorption isotherm experiments were performed with initial Cd(II) concentrations of 5, 10, 15, 25, 50, 80, 100, 150, $200 \mathrm{mg} \mathrm{L}^{-1}$ and $\mathrm{Pb}$ (II) concentrations of 10, 25, 50, 100, $200,400,600,800,1000 \mathrm{mg} \mathrm{L}^{-1}$, respectively. The relative metal ion concentration of the aqueous solution in contact with ST750 were sampled and measured at regular time intervals. A syringe filter with a $0.45 \mu \mathrm{m}$ pore size membrane was used to filter the suspensions after adsorption. The removed sample solution was diluted with distilled water. The aqueous solutions in each flask with $\mathrm{Cd}(\mathrm{II})$ and $\mathrm{Pb}(\mathrm{II})$ concentrations were mixed well by shaking and analyzed by ICP-OES.

\subsection{Data analysis}

2.5.1. Adsorption kinetics. The adsorption capacity $\left(q_{\mathrm{t}}\right)$ of ST before and after thermal activation for $\mathrm{Cd}$ (II) and $\mathrm{Pb}$ (II) uptake was calculated by the following equation:

$$
q_{\mathrm{t}}=\left(C_{0}-C_{\mathrm{t}}\right) V / m
$$

where $q_{\mathrm{t}}$ was the amount of heavy metal cations adsorbed (mg $\left.\mathrm{g}^{-1}\right)$ at any time $t(\mathrm{~min}) . C_{0}$ and $C_{\mathrm{t}}\left(\mathrm{mg} \mathrm{L}^{-1}\right)$ were the initial and remaining $\mathrm{Cd}(\mathrm{II})$ and $\mathrm{Pb}(\mathrm{II})$ concentrations, respectively. $V$ (L) was the volume of the suspension; $m(\mathrm{~g})$ was the adsorption capacity of heavy metals.

The experimental data were described by the widely used pseudo-first order and pseudo-second order models, which are generally expressed as follows:

$$
\begin{gathered}
q_{\mathrm{t}}=q_{\mathrm{e}}\left(1-\mathrm{e}^{-k_{1} t}\right) \text { (pseudo-first order equation) } \\
q_{\mathrm{e}}=\frac{q_{\mathrm{e}}^{2} k_{2} t}{1+q_{\mathrm{e}} k_{2} t}(\text { pseudo-second order equation) }
\end{gathered}
$$

The linear form of the pseudo-second order equation can be described as:

$$
\frac{t}{q_{\mathrm{t}}}=\frac{1}{k_{2} q_{\mathrm{e}}^{2}}+\frac{t}{q_{\mathrm{e}}}
$$

where $q_{\mathrm{e}}$ was the amount of $\mathrm{Cd}(\mathrm{II})$ or $\mathrm{Pb}(\mathrm{II})$ adsorbed $\left(\mathrm{mg} \mathrm{g}^{-1}\right)$ at equilibrium, and $k_{1}$ was the rate constant of pseudo-first-order kinetics model accompanying the physical quantity unit of $\min ^{-1} . k_{2}$ was the rate constant of pseudo-second-order kinetics model accompanying a physical quantity unit of $\mathrm{g}$ $\mathrm{mg}^{-1} \min ^{-1}$.

To determine whether intra-particle diffusion was the ratelimiting step of adsorption for heavy metal cations, the intraparticle diffusion model was suggested. It can be expressed as follows:

$$
q_{\mathrm{t}}=K_{\mathrm{id}} t^{0.5}+C \text { (intra-particle diffusion model) }
$$

where $k_{\mathrm{id}}$ is the intraparticle diffusion rate constant $(\mathrm{mg}$ ( $\mathrm{g}$ $\left.\min ^{0.5}\right)^{-1}$ ). $C$ is a constant related to the boundary layer thickness.

2.5.2. Adsorption isotherm. Adsorption isotherms were fitted using the Langmuir and Freundlich models.

Langmuir model:

$$
q_{\mathrm{e}}=\frac{q_{\mathrm{max}} K_{\mathrm{L}} C_{\mathrm{e}}}{1+K_{\mathrm{L}} C_{\mathrm{e}}}
$$

The linear forms of the Langmuir model can be described as:

$$
\frac{C_{\mathrm{e}}}{q_{\mathrm{e}}}=\frac{1}{K_{\mathrm{L}} q_{\max }}+\frac{C_{\mathrm{e}}}{q_{\max }}
$$

where $C_{\mathrm{e}}\left(\mathrm{mg} \mathrm{L}^{-1}\right)$ represents the equilibrium concentration of $\mathrm{Cd}(\mathrm{II})$ and $\mathrm{Pb}(\mathrm{II})$ in the aqueous solutions, $K_{\mathrm{L}}\left(\mathrm{L} \mathrm{mg}^{-1}\right)$ represents the Langmuir adsorption affinity parameter, while $q_{\mathrm{e}}$ and $q_{\max }\left(\mathrm{mg} \mathrm{g}^{-1}\right)$ represent the equilibrium adsorption capacity and maximum adsorption capacity, respectively.

Freundlich model:

$$
q_{\mathrm{e}}=K_{\mathrm{F}} C_{\mathrm{e}}^{n}
$$

The linear forms of the Freundlich model can be described as:

$$
\log q_{\mathrm{e}}=\log K_{\mathrm{F}}+\frac{1}{n} \times \log C_{\mathrm{e}}
$$

where $K_{\mathrm{F}}\left(\mathrm{mg} \mathrm{g}^{-1}\left(\mathrm{mg} \mathrm{L}^{-1}\right)^{-1 / n}\right)$ is the Freundlich distribution coefficient, and $1 / n$ is empirical constant of the Freundlich describing the adsorption intensity or surface heterogeneity.

\section{Results and discussion}

\subsection{Properties of straw tufa}

The composition of the natural ST was evaluated by XRF. The results were listed in Table 1 . It is mainly composed of $\mathrm{Ca}, \mathrm{Si}, \mathrm{Al}$ and $\mathrm{Fe}$. Its $\mathrm{Ca}, \mathrm{Si}, \mathrm{Al}$, and $\mathrm{Fe}$ contents were $53.49 \%, 12.51 \%$, $3.80 \%$ and $3.91 \%$, respectively. However, much lower $\mathrm{K}$, Ti and 
Table 1 Composition of ST

\begin{tabular}{llllllll}
\hline Sample & $\mathrm{Ca}$ & $\mathrm{Si}$ & $\mathrm{Al}$ & $\mathrm{Fe}$ & $\mathrm{K}$ & $\mathrm{Ti}$ & $\mathrm{Sr}$ \\
\hline $\mathrm{Wt} / \%$ & 53.491 & 12.507 & 3.804 & 3.922 & 1.031 & 0.751 & 0.235
\end{tabular}

Sr contents were found in the ST with values of $1.03 \%, 0.75 \%$ and $0.24 \%$, respectively.

The $\mathrm{N}_{2}$ adsorption-desorption isotherm and BJH adsorption pore size distributions of the natural ST were explored. Fig. 1(a)
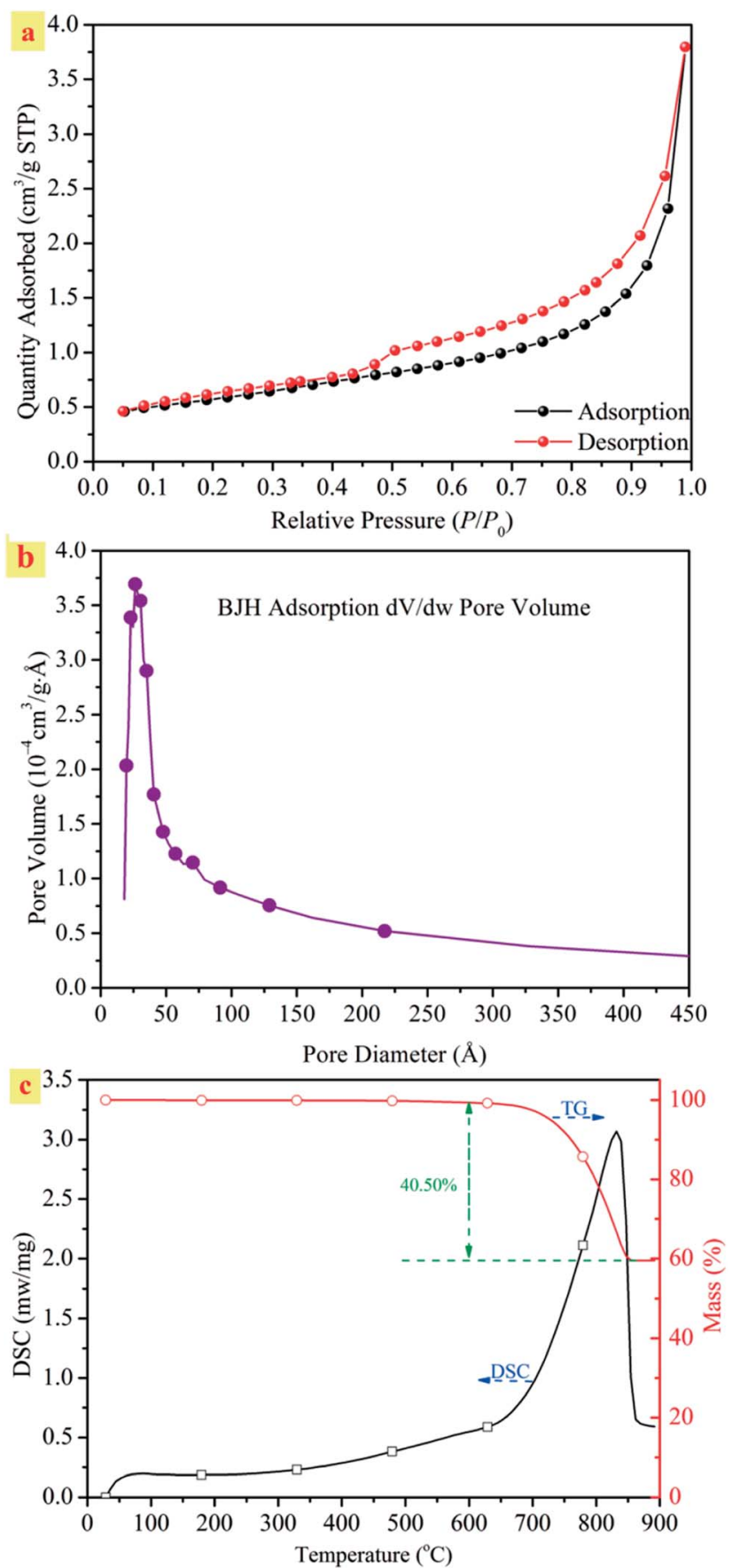

Fig. 1 (a) BET surface area plot. (b) Pore size distribution. (c) TG-DSC profiles obtained for ST. shows the $\mathrm{N}_{2}$ adsorption-desorption isotherms of the sample. The ST belonged to the typical type IV of adsorption isotherms with a H1 hysteresis loop, which is characteristic of mesoporous structures. The steepness of the capillary condensation step suggested the presence of mesopores, which was further confirmed by the pore size distribution shown in the inset of Fig. 1(b). The desorption isotherm was at the top of the adsorption isotherm, accompanied by producing adsorption hysteresis. The ST was mesoporous with a large specific surface area of $427.0 \mathrm{~m}^{2} \mathrm{~g}^{-1}$ and a pore diameter of $11.77 \mathrm{~nm}$. The natural mesoporous structures form a basis of a high efficiency for the uptake of heavy metal cations by the ST and allow a direct water discharge after metal removal without any other treatment.

The TG-DSC technique was used to investigate the thermal behavior of ST, which could provide the necessary data for the following decomposition process. Fig. 1(c) shows the typical TGDSC curves of the natural straw tufa. As shown in the DSC curve, a broad endothermal peak from 650 to $850{ }^{\circ} \mathrm{C}$ involved the decomposition reaction of carbonate ores. An endothermal peak was centered at $829{ }^{\circ} \mathrm{C}$ for the ST. The endothermal peak demonstrated a phase change, indicating the formation of a new mineral. In addition, an obvious weight loss peak appeared from $700{ }^{\circ} \mathrm{C}$ in the TG curve. The breaking up of the crystal lattice was accompanied by a $40 \%$ weight loss due to the decomposition reaction of calcite with $\mathrm{CO}_{2}$ releasing.

\subsection{Properties of $\mathbf{S T}$ after thermal activation}

Fig. 2(a) presents the functional groups of ST. The adsorption bands appearing at $1390 \mathrm{~cm}^{-1}$ and $1792 \mathrm{~cm}^{-1}$ were associated with the $\mathrm{C}-\mathrm{O}$ stretching vibration band and $\mathrm{C}-\mathrm{O}$ antisymmetric stretching vibration, respectively. The $\mathrm{CO}_{3}{ }^{2-}$ external deformation vibration peak was observed at a frequency of $876 \mathrm{~cm}^{-1}$. The $1003 \mathrm{~cm}^{-1}$ peak was associated with $\mathrm{Si}-\mathrm{O}$ deformation vibration in plane referred to $\mathrm{SiO}_{3}{ }^{2-}$. It indicated that the ST before and after thermal activation has no obvious change. $\mathrm{X}$ ray diffraction (XRD) was used to characterize the phase composition of ST, ST-600 and ST-750. As shown in Fig. 2(b), there was little obvious change on the diffraction peaks of the ST before and after thermal activated, indicating that the composition of the sample before and after thermal activated has no significant change. A part of the sample belongs to calcite with the similar diffraction peaks related to the (012), (104), (006), (110), (113), (202), (018), (024), (112), (119) and (300) planes (PDF 05-0586 ${ }^{\#}$. The other part of the sample belongs to $\mathrm{SiO}_{2}$ with the analogical diffraction peaks related to the (100) and (011) planes (PDF 85-0794 $4^{\#}$. As you see, ST was primarily composed of calcite and $\mathrm{SiO}_{2}$, which was also supported by the result of XRF.

Fig. 3 presents the SEM photographs of the ST before and after thermal activation. As illustrated in Fig. 3(a), the spatial structure of the ST shows a three-dimensional reticulate structure. There are interconnected caves and drill ways in the cage construction. This might be the main reason for that water absorption for ST is very strong. As shown in Fig. 3(b), the fossilized features of calcium carbonate bryophyte can be 

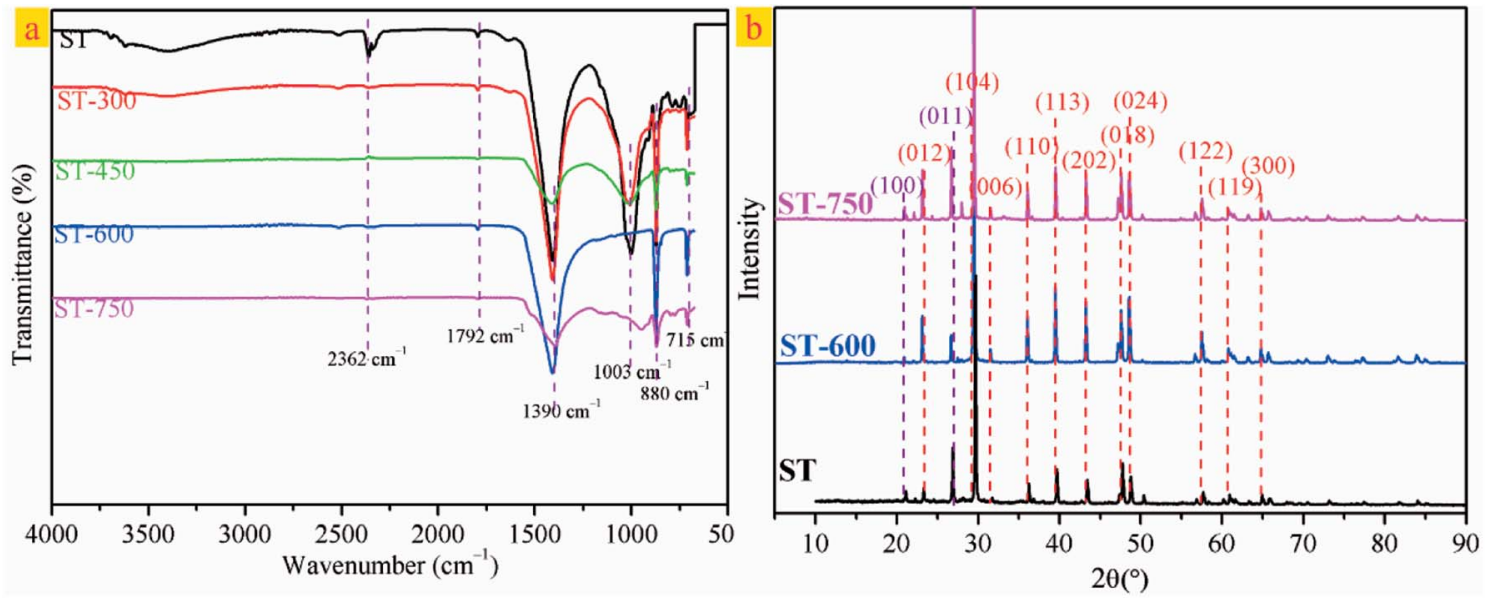

Fig. 2 (a) FT-IR spectra for ST, ST-300, ST-450, ST-600 and ST-750.

(b) XRD profiles obtained for ST, ST-600 and ST-750.

clearly reflected on the pore wall of the interconnected caves and drill ways. After thermal activation at 300 and $450{ }^{\circ} \mathrm{C}$, the coralliform and perforated structure of the sample could be seen clearly, (see Fig. 3(c) and (d)). The interconnected caves and drill ways are connected to each other through openings, effectively increasing the specific surface area with cave effects. As can be seen in Fig. 3(e), the phenomenon is more pronounced with increasing the thermal activation temperature up to $600{ }^{\circ} \mathrm{C}$. Most of the surface has collapsed and the edge of the pore began to collapse. To move forward a single step, the pore aperture of the sample has been enlarged to approximately $2 \mathrm{um}$ and the edge of the pore continues to collapse with continuously increasing the thermal activation temperature to $750{ }^{\circ} \mathrm{C}$, as seen in Fig. 3(f). Three-dimensional mesoporous calcium carbonate-silica frameworks, which could be described a coralliform and perforated structure, have been successfully synthesized from porous fossil bryophyte by the thermally activation technique. These porous structural features could lead to a selective adsorption capacity of a molecular sieve and strong super-pore effects, and effectively increase the surface area and enhance the adsorption activity site. In addition, the mesoporous molecular structure forms a large electrostatic attraction accompanied by a considerable degree of stress. The internal stress will give rise to a preferential adsorption of heavy metal ions that is selective and efficient.

\subsection{Adsorption kinetics}

To understand the dynamic interaction of the heavy metal cations of Cd(II) with the ST before and after thermal activation, and to predict the time required for adsorption equilibrium, ST and ST-750 were added as initial solid adsorbent into an aqueous solution with a known Cd(II) concentration at $298.1 \mathrm{~K}$. Then, the metal cation concentration in the aqueous solution was measured by ICP-OES at regular intervals. The experimental amounts of $\mathrm{Cd}(\mathrm{II})$ adsorbed over time are plotted in Fig. (4),
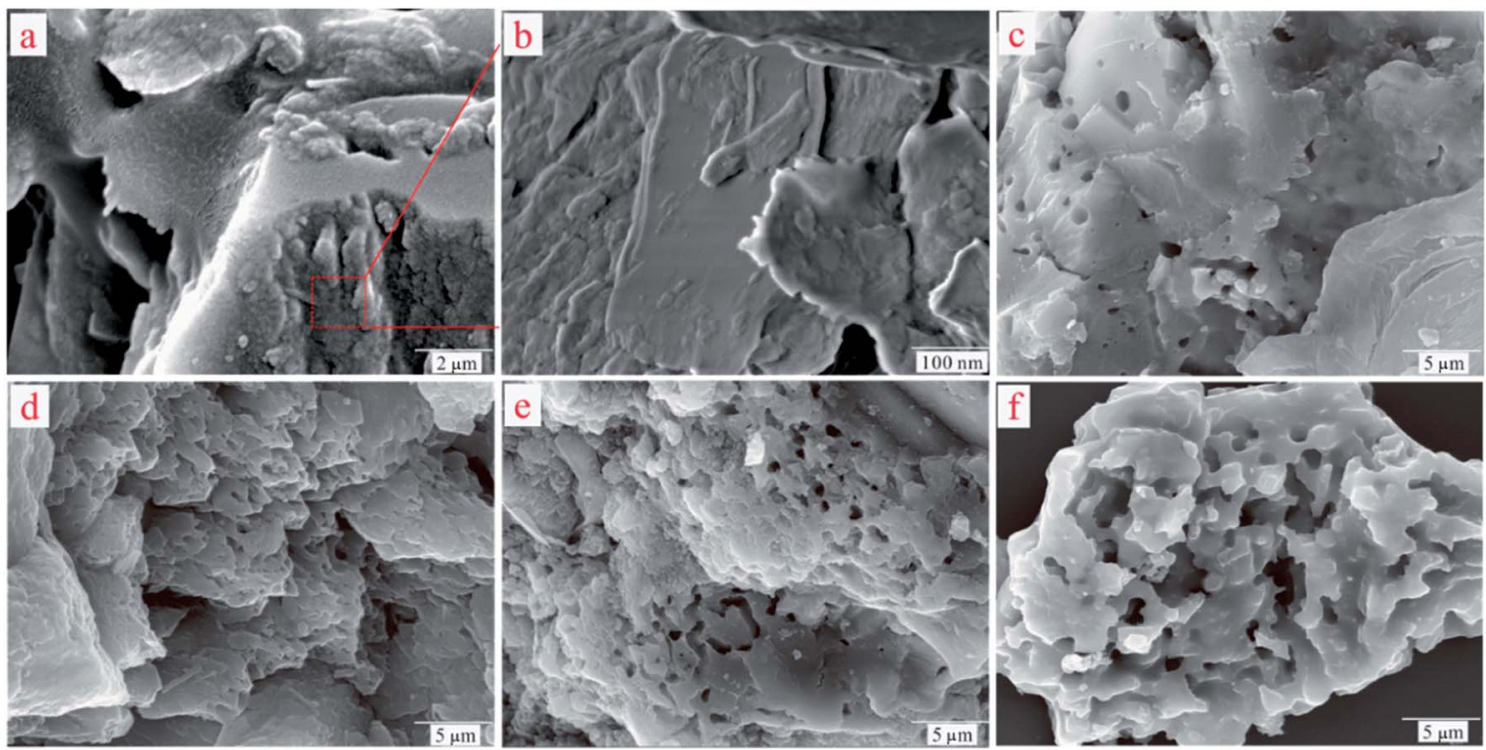

Fig. 3 (a) SEM images of ST. (b) Magnified view of the red square region in (a). (c) SEM image of ST-300. (d) SEM image of ST-450. (e) SEM image of ST-600. (f) SEM image of ST-750. 

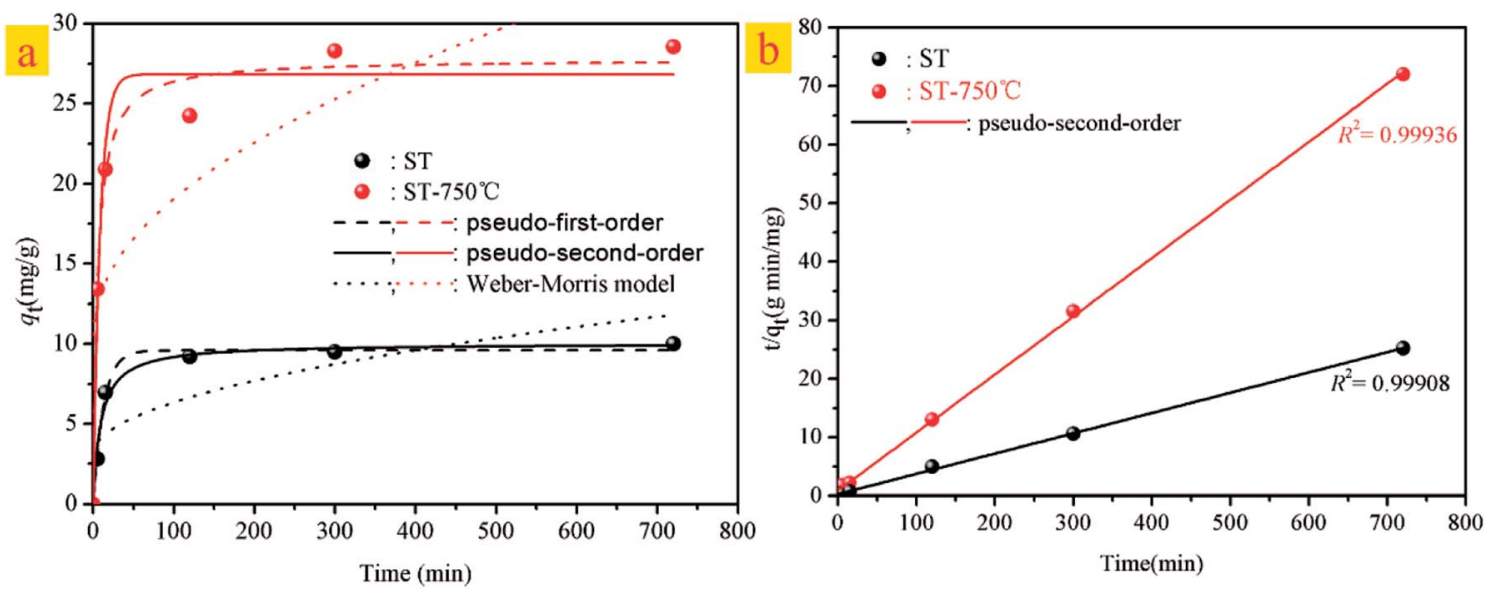

Fig. 4 (a) Kinetic models for Cd(॥)adsorption on ST and ST-750. (b) The linear analysis of pseudo-second-order kinetics model for Cd(॥) adsorption on ST and ST-750.

which presents the influence of reaction time on the adsorption rate of Cd(II) with the ST and ST-750 as the adsorbent. The Cd(II) adsorption amount on ST and ST-750 reached $10.05 \mathrm{mg} \mathrm{g}^{-1}$ and $28.55 \mathrm{mg} \mathrm{g}^{-1}$. The $\mathrm{Cd}$ (II) concentration in the aqueous solution first sharply increases in the first 100 min step before reaching adsorption equilibrium. Then, it is followed by a relatively slower increase. The drastically increasing section of the adsorption can be understood as a result of the sufficient active adsorption sites on the ST and ST-750 interface exposed to Cd(II) at the beginning of each experiment, and the decreasing section of adsorption can be interpreted as that of active adsorption sites taken up as time goes on. The decreasing section of adsorption can also be attributed to the decrease of the BET surface area, which is consistent with the increasing average pore diameter of the ST during the demineralization process. This may be caused by the removal of minerals incorporating $\mathrm{K}$ and $\mathrm{Sr}$ and the enlargement of the pores existing in the natural porous structure, resulting in the pore diameter increasing and ash content decreasing. This finding indicates that relatively less polar functional groups and less aromatic structures are present. The highest concentrations detected during each experimental process could be assigned as the equilibrium adsorption capacity of the initial solid phase in this work. It is obvious that a duration of at least 100 min was needed for the aqueous solution of $\mathrm{Cd}$ (II) with ST and ST-750 to reach adsorption equilibrium if ST and ST-750 were added to the solution as the initial solid phase in a $100 \mathrm{mg} \mathrm{L}^{-1} \mathrm{Cd}(\mathrm{II})$ aqueous solution.

Furthermore, the kinetic mechanism of Cd(II) adsorption with the ST and ST-750 as adsorbent also followed the pseudo first-order kinetic model and pseudo second-order kinetic model, as described in eqn (2) and (3). The predicted fitting curves of the two kinetic models are plotted in Fig. 4(a), with the dashed lines calculated from the pseudo first-order kinetic model and the solid lines calculated from the pseudo secondorder kinetic model. The relevant parameters of the pseudo first-order kinetic model and pseudo second-order kinetic model are tabulated in Table 2. According to the correlation coefficient value $R^{2}$, the experimental data of Cd(II) adsorption were better fitted by the pseudo second-order kinetic model because of a higher value of $R^{2}$.

In addition, the pseudo-second-order adsorption kinetics model estimated via linear analysis using eqn (4) was shown in Fig. 4(b). It can be found that the calculated values for the equilibrium adsorption capacity predicted by the pseudo second-order kinetics model possessed a high consistence with the experimental values. The $R^{2}$ of linear form of pseudosecond-order adsorption kinetics model is 0.9830 and 0.9841 for ST and ST-750, respectively. Therefore, the pseudo secondorder kinetic model was used to evaluate the whole adsorption equilibrium process. In regard to these two kinetic models, it can be noted that the pseudo first-order kinetic model views the rate of occupation of the adsorption active sites to be proportional to the number of unoccupied sites, while the pseudo second-order kinetic model depicts the rate limiting step as the formation of a chemisorptive bond involving valence forces, namely, the sharing or exchange of electrons between the sorbent and sorbate. Obviously, the agreement of the predicted and experimental data for adsorption of Cd(II) shows the adsorption of Cd(II) with ST and ST-750 as the adsorbent occurs

Table 2 Kinetic parameters for Cd(॥)adsorption on ST and ST-750

\begin{tabular}{|c|c|c|c|c|c|c|c|c|c|}
\hline ST-750 & 26.83 & 0.1196 & 0.9674 & 27.78 & 0.00674 & 0.9841 & 0.8506 & 10.5554 & 0.5558 \\
\hline
\end{tabular}


by chemical adsorption, and the rate limiting step stems from the conjugation between the ST before and after thermal activation and heavy metal cations. As shown in Fig. 4(a), the intraparticle diffusion model was also used to evaluate the dynamic interaction of the heavy metal cations Cd(II) with ST and ST-750 as the adsorbent by using eqn (5). According to the intra-particle diffusion model, if the rate limiting step is the intra-particle diffusion, the $q_{\mathrm{t}}$ plotted against the square root of time should be a straight line and pass through the origin $(C=0)$, the deviation of the plot from the linearity indicates that the ratelimiting step should be boundary layer (film) diffusion. As can be seen in Fig. 4(a), the calculation result indicates that the intra-particle diffusion is not the rate limiting step and the rate limiting step is the formation of chemisorptive bond involving valence forces.

\subsection{Adsorption isotherm}

Adsorption isotherms were performed to evaluate the adsorption performance of the ST before and after thermal activation in contact with $\mathrm{Cd}(\mathrm{II})$ at $T=298.1 \mathrm{~K}$, through which the relationship between absorbent concentration and the adsorption capacity was further investigated. The adsorption isotherms of Cd(II) onto ST, ST-300, ST-450, ST-600, and ST-750 are shown in Fig. (5). To construct the adsorption capacity regions of Cd(II) as a function of activation temperature and initial equilibrium concentration, an adsorption mechanism model is necessary to simulate and predict the adsorption properties of ST, ST-300, ST-450, ST-600 and ST-750. As discussed in previous studies, the widely used Langmuir and Freundlich models are sufficient for this task. Then, the experimental data were calculated by using eqn (6) and (8) of the Langmuir and Freundlich models, with the calculated results plotted in Fig. (5) and with the model parameters tabulated in Table 3. Applying the model parameters in Table 3, we predicted the adsorption isotherms of $\mathrm{Cd}$ (II) with ST, ST-300, ST-450, ST-600 and ST-750 as the adsorbent in the aqueous solution. The calculated results from Freundlich model deviate largely from our experimental data of adsorption capacity. The calculated results from Langmuir model are highly consistent with our experimental data for the adsorption capacity. The Langmuir model is apparently necessary to describe the properties of the system.

The adsorption capacity of $\mathrm{Cd}(\mathrm{II})$ in the aqueous solution during the adsorption process as a function of aqueous equilibrium concentration is presented in Fig. 5. As illustrated, the adsorption capacity of $\mathrm{Cd}$ (II) with ST before and after thermal activation as the adsorbent increased drastically at first and then remained unchanged. In $\mathrm{Cd}$ (II) aqueous solution at 298.1 $\mathrm{K}$, the equilibrium adsorption capacity $q_{\mathrm{e}}$ increases with the aqueous equilibrium concentration of $\mathrm{Cd}(\mathrm{II})$ increasing. $\mathrm{A}$ comparison of the correlation coefficients $\left(R^{2}\right.$, Table 4$)$ indicates that the adsorption of Cd(II) onto ST, ST-300, ST-450, ST-600, and ST-750 can be well fit using a Langmuir model with a correlation coefficient of $0.9740,0.9773,0.9915,0.9978$, and 0.9297. As illustrated by the constant values in the Langmuir model, the maximum adsorption capacity $\left(q_{\max }\right)$ value of $\mathrm{Cd}(\mathrm{II})$ adsorbed onto ST, ST-300, ST-450, ST-600, ST-750 were 14.05 mg $\mathrm{g}^{-1}, 12.76 \mathrm{mg} \mathrm{g}^{-1}, 14.09 \mathrm{mg} \mathrm{g}^{-1}, 17.00 \mathrm{mg} \mathrm{g}^{-1}$ and $33.81 \mathrm{mg} \mathrm{g}^{-1}$ respectively. Previous studies have demonstrated that the natural calcium carbonate had a low adsorption capacity of $18.52 \mathrm{mg} \mathrm{g}^{-1}$ for $\mathrm{Cd}^{2+} .{ }^{37}$ Thermal activated serpentine at $700{ }^{\circ} \mathrm{C}$ exhibited a maximum adsorption capacity of $15.21 \mathrm{mg} \mathrm{g}^{-1}$ for
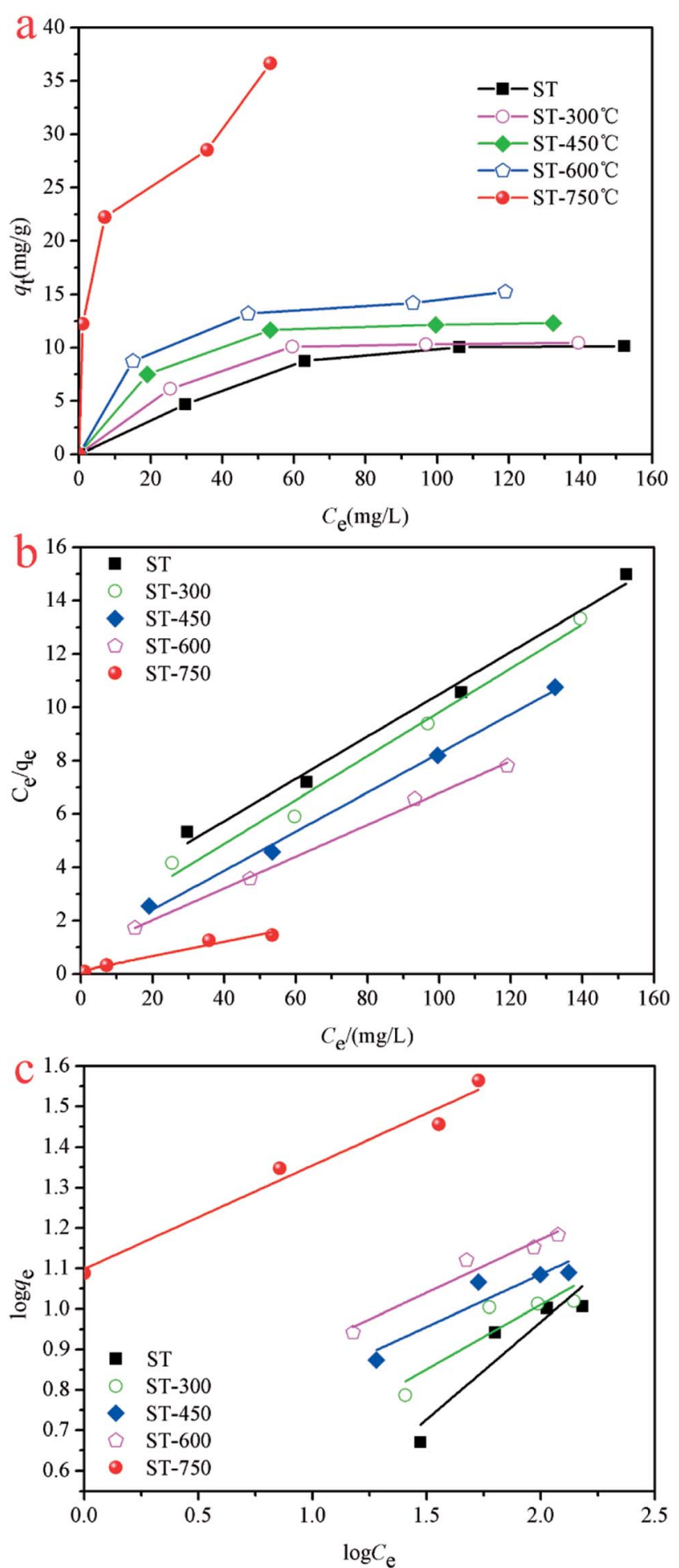

Fig. 5 (a) Isotherms of $\mathrm{Cd}(\Perp)$ adsorption on ST and ST-T as a function of temperature. (b) Linear fitting curves with Langmuir model on ST and ST-T. (c) Linear fitting curves with Freundlich model on ST and $\mathrm{ST}-\mathrm{T}$. 
Table 3 Langmuir and Freundlich isotherm model parameters for adsorption of Cd(॥) on ST

\begin{tabular}{lllllll}
\hline & \multicolumn{2}{l}{ Langmuir isotherm } & & & \multicolumn{2}{c}{ Freundlich isotherm } \\
\cline { 2 - 3 } Adsorbent & $q_{\max }\left(\mathrm{mg} \mathrm{g}^{-1}\right)$ & $K_{\mathrm{L}}\left(\mathrm{L} \mathrm{mg}^{-1}\right)$ & $R^{2}$ & & $K_{\mathrm{F}}\left(\mathrm{L} \mathrm{mg}^{-1}\right)$ & $n$ \\
\hline ST & 14.05 & 0.02091 & 0.9740 & 1.4746 & 0.3981 \\
ST-300 & 12.76 & 0.04283 & 0.9773 & 2.8979 & 0.9459 \\
ST-450 & 14.09 & 0.0654 & 0.9915 & 4.1547 & 0.9525 \\
ST-600 & 17.00 & 0.0737 & 0.9978 & 4.7244 & 0.9717 \\
ST-750 & 33.81 & 0.3975 & 0.9297 & 12.6689 & 0.2474 \\
\end{tabular}

Table 4 Isotherm parameters of $\mathrm{Cd}(॥)$ adsorption $\mathrm{Pb}(॥)$ adsorption by ST-750 at $298.1 \mathrm{~K}, 308.1 \mathrm{~K}, 318.1 \mathrm{~K}$

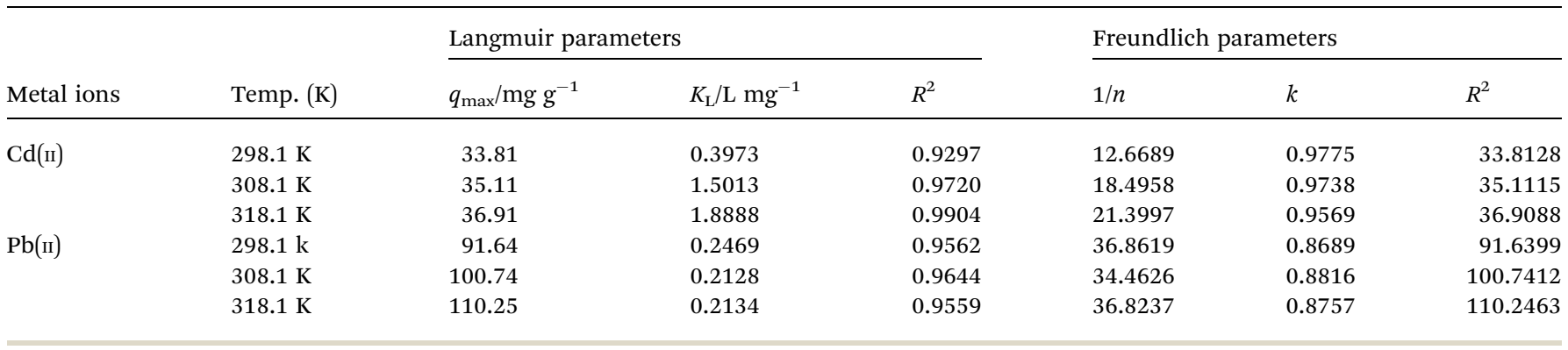

$\mathrm{Cd}^{2+}$ removal. ${ }^{38}$ In comparison, the straw tufa modified allows it to be widely used in artificial wetland landfill and environmental protection. Furthermore, the adsorption isotherm model for the adsorption of Cd(II) on different ST samples estimated via linear analysis of the data using eqn (7) and (9) were shown in Fig. 5(b) and (c). It is clearly observed that the Langmuir model was more suitable for describing the adsorption behavior of $\mathrm{Cd}(\mathrm{II})$ on the adsorbents than the Freundlich model. All samples showed the same trends. This phenomenon occurs because there are many more occupied active adsorption sites in low $\mathrm{Cd}$ (II) initial concentration aqueous solution, while fewer occupied active adsorption due to active adsorption sites that existed in the high $\mathrm{Cd}(\mathrm{II})$ initial concentration aqueous solution when active adsorption sites were saturated by Cd(II) up to equilibrium. With an increase in temperature, the maximum adsorption capacity $q_{\max }$ required for complete adsorption increases.

The major difference in adsorption capacity implies that ST after thermal activation was an excellent adsorption material, possessing high adsorption efficiency towards template ions. In addition, these curves depicted that the saturated adsorption capacity increased with increasing temperature. The adsorption capacity changes can be explained since the ST before and after thermal activation was a temperature-responsive imprinted porous material whose adsorption behavior was highly effected by both the imprinted cavities situation and the temperature responsive behaviors. The surface area of the ST after calcination have be measured for better understanding of adsorption mechanism of heavy metals by using $\mathrm{N}_{2}$ adsorption-desorption isotherm. The surface areas of ST $<$ ST-300 $<$ ST-450 $<$ ST- $600<$ ST-750 were 427.0, 462.3, 669.4, 1275.1 and $1589.6 \mathrm{~m}^{2} \mathrm{~g}^{-1}$, respectively, which has increased with the activation temperature increasing. The Langmuir model is the basic assumption that monolayer adsorption occurs on the surface within the sorbent of a finite number of specific homogeneous sites. The adsorption sites were assumed to be energetically equivalent, as well as distant from each other, so that no interaction existed between the adjacent adsorbed molecules. Our experimental data indicate that the removal of Cd(II) with ST, ST-300, ST-450, ST-600, and ST-750 as adsorbents predominantly conforms to the monolayer adsorption. The mineral content and porous structures of the ST after thermal activation may contribute to the higher adsorption capacity for $\mathrm{Cd}(\mathrm{II})$. It is also presumed that all binding sites on the sorbent surface are free sites that are ready to accept the sorbent from solution.

\subsection{Adsorption mechanism}

In order to determine the chemical environment and microstructure of ST after Cd(II) adsorption, TEM and EDX measures have been performed with the results exhibited in Fig. 6. The peak of Cd elements can be clearly observed in Fig. 6(a1) and 6(a2). In order to further analyze the distribution of Cd element in the sample, the EDX analysis was conducted in the middle and marginal regions of the Fig. 6(a), as shown in Fig. 6(a1) and 6(a2), respectively. As can be seen, the peak of the Cd element in Fig. 6(a1) is lower than Fig. 6(a2). This means that the content of $\mathrm{Cd}$ in the peripheral region was greater than that in the middle region on the ST after the adsorption of Cd(II). The adsorbed Cd mainly exists on the surface of the sample rather than the interior. As shown in Fig. 6(b), the crystal particle with irregular distribution can be seen explicitly in the amorphous $\mathrm{SiO}_{2}$. In order to further understand the microstructure and morphology of the crystal particles, the depth magnification and diffraction pattern of the randomly selected crystal particles were analyzed. The results are shown in Fig. 6(b1) and 6(b2). As can be seen in Fig. 6(b1), the crystal particle with size 

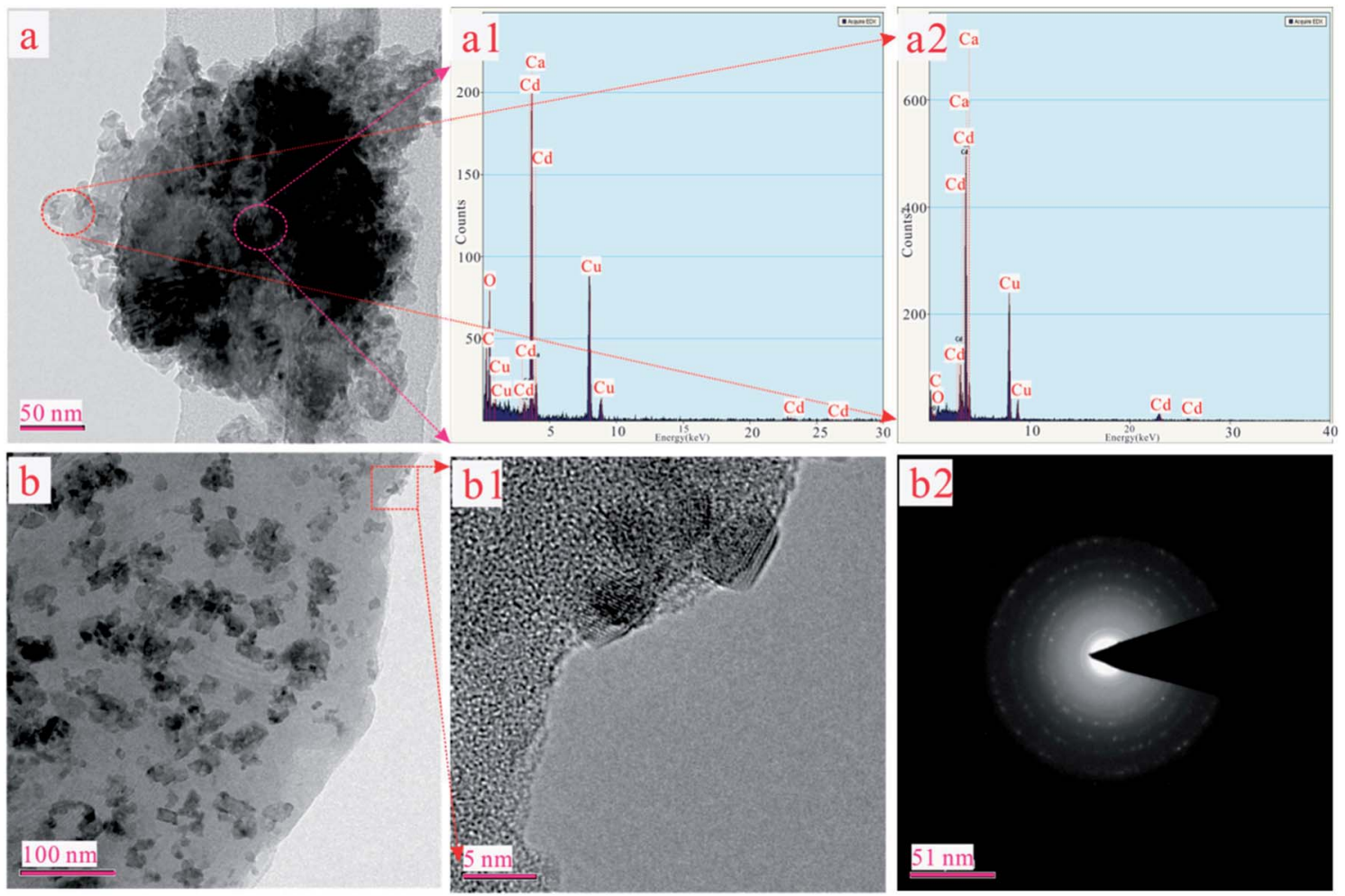

Fig. 6 (a) TEM images of ST-750 after the adsorption of Cd(॥). (a1 and a2) Corresponding EDX elemental mapping images of (a). (b) TEM image of silica nanosheet of ST-750 after the adsorption of Cd(॥). (b1) Magnified view of the red square region in (b). (b2) The diffraction pattern of (b1).

of about $5 \mathrm{~nm}$ was embedded onto the surface of sample. And there is an outline in the halo of the diffraction pattern as presented in Fig. 6(b2). It is suspected that $\mathrm{CdCO}_{3}$ may be generated on the $\mathrm{SiO}_{2}$ surface of the ST.

In addition, the XRD patterns of the different ST samples after adsorbed Cd(II) were given in Fig. 7. As shown in Fig. 7(a), the ST, ST-600 and ST(SD)-750 after adsorption of Cd(II) have the broadly consistent diffraction peaks related to the (012), (104), (006), (110), (113), (202), (018) (024), (112), (119), (300) planes contributed to calcite (PDF 05-0586 ${ }^{\#}$ ) and (100), (011) planes (PDF 85-0794 ) contributed to silica. By carefully analyzing the Fig. 7(a) and enlarging it into Fig. 7(b), the XRD patterns of the samples after $\mathrm{Cd}(\mathrm{II})$ ion adsorption did change slightly. For the sake of convenience, these areas have been marked as S1, S2, S3, and $\mathrm{S} 4$ regions in Fig. 7(b). As can be seen, the diffraction peaks of $20.87^{\circ}(2 \theta)$ and $28.31^{\circ}(2 \theta)$ disappeared ascribed to $\mathrm{SiO}_{2}$ (PDF $\left.85-0794^{\#}\right)$ in the region of S1, S3. The diffraction peaks of $24.45^{\circ}$ $(2 \theta)$ disappeared ascribed to calcite (PDF 03-0612 $2^{\#}$ ) in the region of S2. The peak width of $30.5^{\circ}(2 \theta)$ gets broaden, indicating that the structure of ST has change due to the more Cd(II) adsorbed in the region of S4. The result means that thermal activation of the ST benefits of the adsorption of $\mathrm{Cd}(\mathrm{II})$.

XPS analyses were carried out to further investigate the adsorbent surface properties and the $\mathrm{Cd}(\mathrm{II})$ adsorption

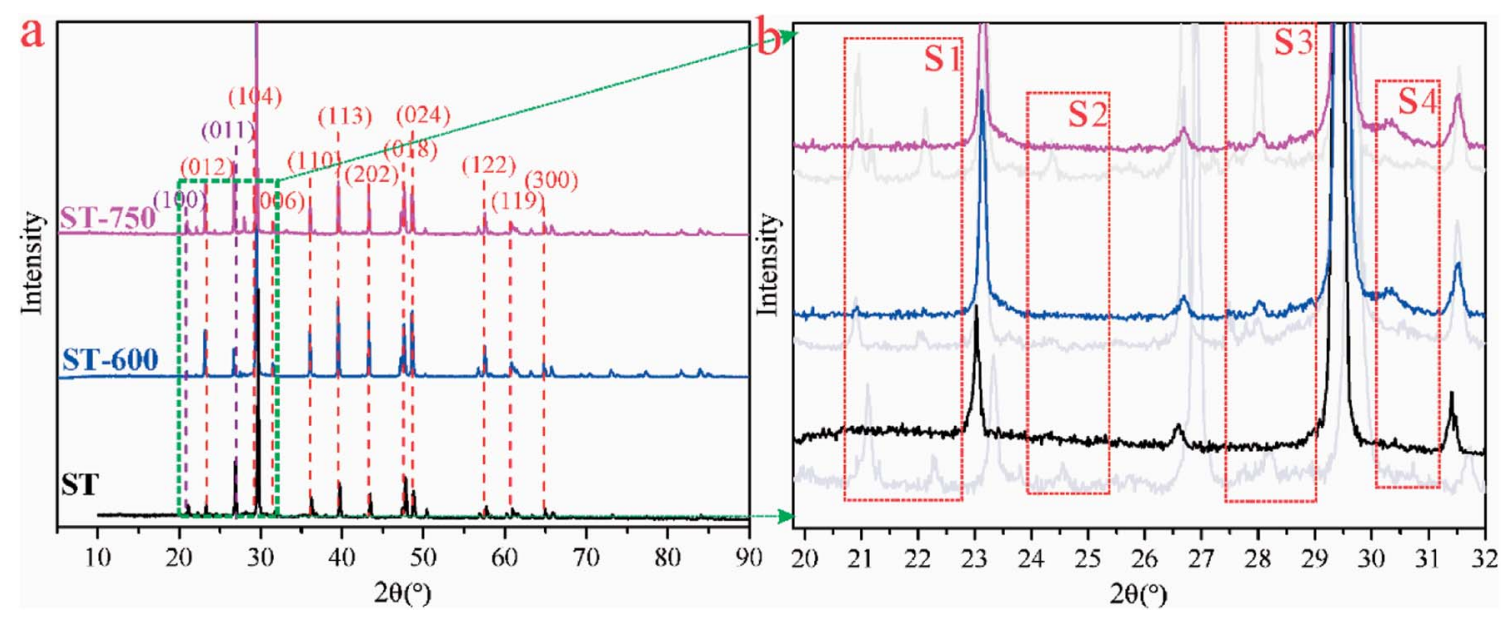

Fig. 7 (a) XRD patterns for ST, ST-600 and ST-750 after adsorption of Cd(॥). (b) Magnified view of the green square region in (a). 
mechanism. The relevant results of the ST and ST-750 after adsorption of $\mathrm{Cd}$ (II) were shown in Fig. 8. The peaks of $\mathrm{Cd} \mathrm{3d}$ distinctly appear in Fig. 8(a). It proved that the Cd(II) ion was successfully adsorbed into the adsorbent, which is consistent with the results of XRD and TEM. As can be seen in Fig. 8(b), there were $\mathrm{C}-\mathrm{O}, \mathrm{C}-\mathrm{C}, \mathrm{C}=\mathrm{C}$ and $\mathrm{CO}_{3}{ }^{2-}$ in the adsorbent after adsorption of $\mathrm{Cd}(\mathrm{II})$. As shown in Fig. 8(c), two peaks of the ST after adsorption of $\mathrm{Cd}(\mathrm{II})$ were varying that is for $\mathrm{CdO}(404.4 \mathrm{eV})$ and for $\mathrm{Cd}(\mathrm{OH})_{2}(405.1 \mathrm{eV})$, which could be assigned to $\mathrm{CdCO}_{3}$ and $\mathrm{Cd}(\mathrm{OH})_{2}$. As can be seen in Fig. 8(d), three peaks of the ST750 after adsorption of $\mathrm{Cd}(\mathrm{II})$ were varying that is for $\mathrm{CdO}(404.4$ $\mathrm{eV})$, for $\mathrm{Cd}(\mathrm{OH})_{2}(405.1 \mathrm{eV})$, for Mont $\mathrm{Cd}(406.7 \mathrm{eV})$, which could be assigned to $\mathrm{CdCO}_{3}, \mathrm{Cd}(\mathrm{OH})_{2}$ and $\mathrm{Cd}\left(\mathrm{HCO}_{3}\right)_{2}$. The above peaks indicated that $\mathrm{Cd}(\mathrm{II})$ on the surface of ST and ST-750 after adsorption of $\mathrm{Cd}(\mathrm{II})$ was present as $\mathrm{CdCO}_{3}(54.44 \%), \mathrm{Cd}(\mathrm{OH})_{2}$ $(45.56 \%)$ and $\mathrm{CdCO}_{3}(39.41 \%), \mathrm{Cd}(\mathrm{OH})_{2}(29.54 \%), \mathrm{Cd}\left(\mathrm{HCO}_{3}\right)_{2}$ (31.05\%), respectively. This indicated the adsorption of $\mathrm{Cd}(\mathrm{II})$ on the natural ST could be ascribed to the precipitation of $\mathrm{CdCO}_{3}$ and $\mathrm{Cd}(\mathrm{OH})_{2}$. Then, the adsorption of $\mathrm{Cd}(\mathrm{II})$ on the ST after thermal activation could be ascribed to the precipitation of $\mathrm{CdCO}_{3}, \mathrm{Cd}(\mathrm{OH})_{2}$ and $\mathrm{Cd}\left(\mathrm{HCO}_{3}\right)_{2}$. Combined with the results of TEM, it can be speculated that cadmium species were primarily in the crystalline $\mathrm{CdCO}_{3}$ precipitation form on all the samples after $\mathrm{Cd}(\mathrm{II})$ adsorbed. Moreover, the peak area corresponding to $\mathrm{CdCO}_{3}$ was higher than that attributed to $\mathrm{Cd}(\mathrm{OH})_{2}$ and $\mathrm{Cd}\left(\mathrm{HCO}_{3}\right)_{2}$. Generally, the adsorption of $\mathrm{Cd}(\mathrm{II})$ on ST was primarily surface precipitation.

\subsection{Competitive adsorption}

To understand the competitive adsorption behavior between $\mathrm{Cd}(\mathrm{II})$ and $\mathrm{Pb}$ (II), the dynamic interaction of the heavy metal cations $\mathrm{Pb}$ (II) with adsorbent ST-750 is necessary. ST-750 was added as an initial solid adsorbent into an aqueous solution with a known $\mathrm{Pb}$ (II) concentration at $298.1 \mathrm{~K}$. As can be observed in Fig. 9(a), the $\mathrm{Pb}$ (II) adsorption had similar tendencies with $\mathrm{Cd}(\mathrm{II})$ adsorption. The $\mathrm{Pb}$ (II) concentration first sharply increased in the first approximately $200 \mathrm{~min}$ and then was followed by a relatively slower process for adsorption. Approximately $300 \mathrm{~min}$ was needed for the $400 \mathrm{mg} \mathrm{L}^{-1} \mathrm{~Pb}$ (II) aqueous solution. Additionally, the pseudo first-order kinetic model and pseudo second-order kinetic model were used to describe the kinetic adsorption of $\mathrm{Pb}$ (II) with the results plotted in Fig. 9(a). Obviously, the pseudo second-order kinetic model could better
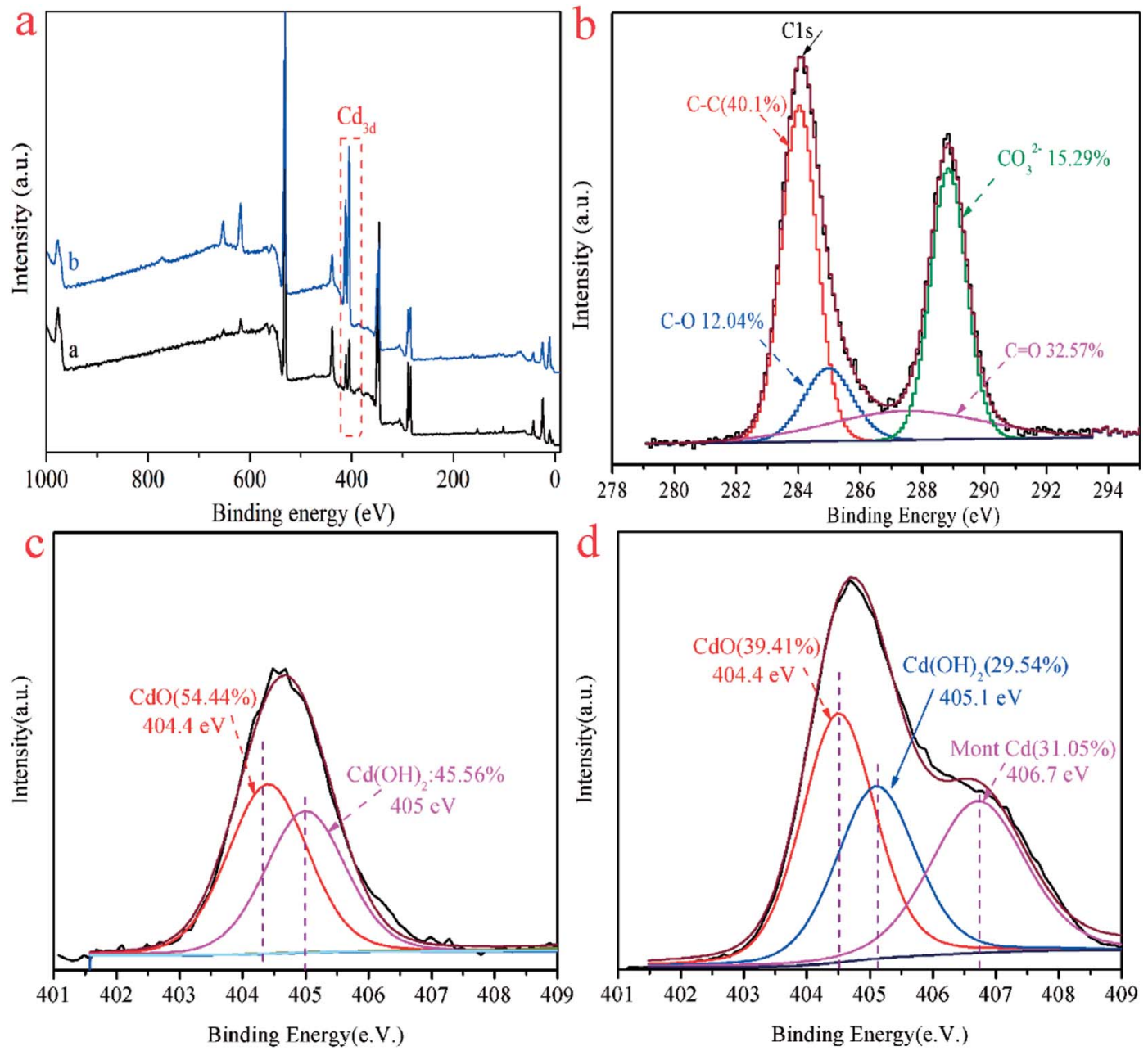

Fig. 8 (a) XPS spectra of ST and ST-750 after adsorption of $\mathrm{Cd}(\Perp)$; (b) $\mathrm{C} 1 \mathrm{~s}, \mathrm{C}-\mathrm{C}, \mathrm{C}-\mathrm{O}, \mathrm{C}=\mathrm{C}$, and $\mathrm{CO}_{3}{ }^{2-}$ spectra of ST after adsorption of $\mathrm{Cd}(\Perp)$; (c) Cd 3d spectra of ST; (d) Cd 3d spectra of ST-750. 

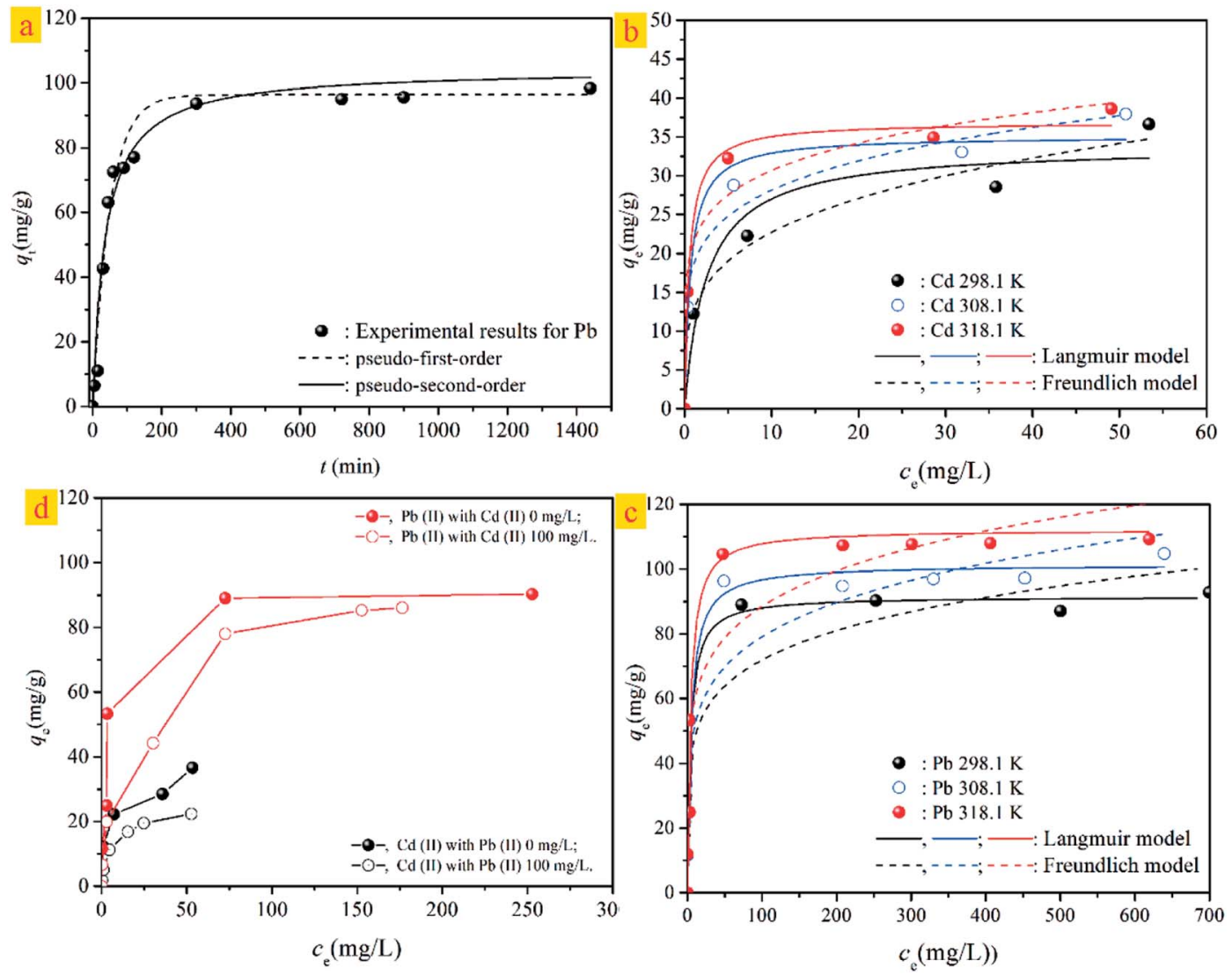

Fig. 9 (a) Kinetic models of ST-750 for Pb(॥)adsorption. (b) Adsorption isotherms of Cd(॥) adsorption on ST-750 as a function of temperature. (c) Adsorption isotherms of $\mathrm{Pb}(॥)$ adsorption on $\mathrm{ST}-750$ as a function of temperature. (d) Competitive adsorption between $\mathrm{Cd}(॥)$ and $\mathrm{Pb}(॥)$.

fit the experimental data indicating that the adsorption of $\mathrm{Pb}$ (II) occurs by chemical adsorption.

The adsorption isotherms of $\mathrm{Cd}(\mathrm{II})$ and $\mathrm{Pb}$ (II) with ST-750 as the adsorbent at $T=298.1,308.1$, and $318.1 \mathrm{~K}$ are shown in Fig. 9(b) and (c). The Langmuir and Freundlich models are applied to simulate and predict the experimental data with the model parameters tabulated in Table 4. Similar to the adsorption of $\mathrm{Cd}(\mathrm{II})$, the adsorption capacity of $\mathrm{Pb}$ (II) first increased and then remained unchanged at each temperature. The Langmuir model closely fits the adsorption of $\mathrm{Cd}(\mathrm{II})$ and $\mathrm{Pb}$ (II) with high correlation coefficients $\left(R^{2}\right.$, Table 4$)$. Compared to $\mathrm{Cd}(\mathrm{II})$, the adsorption of $\mathrm{Pb}(\mathrm{II})$ is much higher; the maximum adsorption capacity $\left(q_{\max }\right)$ values of $\mathrm{Pb}$ (II) adsorbed were $91.591 \mathrm{mg} \mathrm{g}^{-1}, 101.323 \mathrm{mg} \mathrm{g}^{-1}$, and $112.192 \mathrm{mg} \mathrm{g}^{-1}$ at $298.1 \mathrm{~K}, 308.1 \mathrm{~K}$ and $318.1 \mathrm{~K}$. This finding can be explained by the hypothesis that the imprinted cavitation matches the template $\mathrm{Pb}$ (II) well in size along with coordination geometries, which benefit $\mathrm{Pb}$ (II) binding with the predetermined recognition sites. $\mathrm{Pb}$ (II) possesses a much lower heat of hydration than Cd(II), which may explain the higher adsorption capacity of $\mathrm{Pb}(\mathrm{II})$ than $\mathrm{Cd}(\mathrm{II})$.

The competitive adsorption between the $\mathrm{Cd}(\mathrm{II})$ and $\mathrm{Pb}(\mathrm{II})$ with ST-750 as the adsorbent has been investigated by studying the adsorption experiments on the influence of the $\mathrm{Cd}(\mathrm{II})$ initial concentration of $100 \mathrm{mg} \mathrm{L}^{-1}$ on the adsorption capacity for $\mathrm{Pb}$ (II) uptake and the influence of the $\mathrm{Pb}$ (II) initial concentration of $100 \mathrm{mg} \mathrm{L}^{-1}$ on the adsorption capacity for Cd(II) removal. The experimental data for competitive adsorption are presented in Fig. 9(d). The adsorption capacity of $\mathrm{Pb}$ (II) is observably greater than that of $\mathrm{Cd}(\mathrm{II})$ accompanying binary aqueous solutions. Comparing the adsorption capacity for the ternary aqueous system with the binary aqueous system, the adsorption capacities of $\mathrm{Cd}$ (II) and $\mathrm{Pb}$ (II) both decrease with the addition of the other heavy metal cations. This indicates that the adsorption of the two ions is hindered by the competitive adsorption. $\mathrm{Pb}$ (II) is more responsive to the adsorbent than $\mathrm{Cd}(\mathrm{II})$, noting that adsorbents are more selective to $\mathrm{Pb}$ (II) than $\mathrm{Cd}(\mathrm{II})$. These results suggest that $\mathrm{Pb}$ (II) has a stronger ability to adsorb on the ST-750 compared to $\mathrm{Cd}(\mathrm{II})$. Thus, the adsorption active sites on the mineral surface are readily exchangeable. The model parameter $K_{\mathrm{L}}$ is related to the affinity between the adsorbent and the adsorbate, with larger $K_{\mathrm{L}}$ values associated with higher affinities. As shown in Table 3, the $K_{\mathrm{L}}$ values in contact with $\mathrm{Pb}(\mathrm{II})$ adsorption onto ST-750 were $0.2469,0.2105$ and 0.2448 at 298.1 $\mathrm{K}, 308.1 \mathrm{~K}$ and $318.1 \mathrm{~K}$. In contrast, the values for $\mathrm{Cd}(\mathrm{II})$ adsorption were $0.0757,0.1483$ and 0.1243 at $298.1 \mathrm{~K}, 308.1 \mathrm{~K}$ and $318.1 \mathrm{~K}$. Collectively, these data provide evidence that ST750 has a higher affinity for $\mathrm{Pb}(\mathrm{II})$ than for $\mathrm{Cd}(\mathrm{II})$.

\section{Conclusions}

In summary, naturally porous fossil bryophyte has been modified by using a thermal activation technique for improving adsorption 
capacity of heavy metals. The surface properties of natural straw tufa were first characterized by BET and TG-DSC. The BET results have ascertained natural mesoporous structures. The ST has specific surface area about $427.0 \mathrm{~m}^{2} \mathrm{~g}^{-1}$ and a pore size at $11.77 \mathrm{~nm}$. Then, X-ray diffraction (XRD) was used to characterize the phase composition of the ST. The ST was primarily composed of calcite and $\mathrm{SiO}_{2}$, which was further supported by the result of XRF. The ST has been activated thermally at 300, 450, 600 and $750{ }^{\circ} \mathrm{C}$. When the ST after thermal activation is further characterized using FT-IR, XRD, and SEM, the interface collapse and porous structural after thermal activation has occurred to form a coralliform and perforated structure. The thermal activated ST can be obtained with very good performance in terms of adsorption capacity and affinities to $\mathrm{Cd}(\mathrm{II})$. The adsorption capacity of the ST can be improved by thermal activation technology, and the capacity was strongly depend on the activation temperature, i.e. the adsorption capacity was increased in the order of ST $<$ ST-300 $<$ ST-450 $<$ ST- $600<$ ST-750, as that performed for ST- $T$. The maximum adsorption capacity of ST-750 is $33.81 \mathrm{mg} \mathrm{g}^{-1}$. The adsorption kinetics can be better described by the pseudo-second-order kinetics model. The adsorption isotherm for $\mathrm{Cd}$ (II) onto different ST samples was well represented by the Langmuir model. By using TEM, XRD and XPS analysis, it proved that the $\mathrm{CdCO}_{3}$ and $\mathrm{Cd}(\mathrm{OH})_{2}$ have generated on the surface of the calcareous tufa. The mechanisms of Cd(II) adsorption onto the calcareous tufa before and after thermal activation could be attributed to ion-exchange, surface complexation, and surface precipitation. Finally, through studying competitive adsorption experiment for $\mathrm{Cd}(\mathrm{II})$ and $\mathrm{Pb}(\mathrm{II})$, the adsorption of the two ions is hindered and the adsorption active sites on the mineral surface are readily exchangeable.

\section{Conflicts of interest}

There are no conflicts of interest to declare.

\section{Acknowledgements}

The authors gratefully acknowledge the financial support of the National Natural Science Foundation of China (Grant No: 21607176), the Natural Science Foundation of Hunan Province, China (Grant No. 2017JJ3516), the Research Foundation of the Education Bureau of Hunan Province, China (Grant No. 16B274), the Open Fund for Key Discipline of Forestry of Central South University of Forestry and Technology (Grant No. 2016ZD11), and the Youth Scientific Research Foundation of Central South University of Forestry and Technology (104|0329).

\section{References}

1 A. Benettayeb, E. Guibal, A. Morsli and R. Kessas, Chem. Eng. J., 2017, 316, 704-714.

2 Q. Q. Zuo, C. Chen, H. J. Cui and M. L. Fu, RSC Adv., 2017, 7, 16238-16243; J. Y. He, Y. L. Li, C. M. Wang, K. S. Zhang, D. Y. Lin, L. T. Kong and J. H. Liu, Appl. Surf. Sci., 2017, 426, 29-39.
3 S. Q. Xiong, J. C. Xu, F. Z. Xie, X. H. Hu, G. H. Gong, Z. Y. Wu and L. M. Yao, Chem. Eng. J., 2017, 316, 383-392.

4 P. S. De Velasco-Maldonado, V. Hernández-Montoya, M. A. Montes-Morán, N. A.-R. Vázquez and M. A. PérezCruz, Appl. Surf. Sci., 2018, 434, 1193-1199.

5 E. Da'na, Microporous Mesoporous Mater., 2017, 247, 145147.

6 W. W. Gong, Y. J. Yu, G. Liang, X. H. Liu, B. S. Cui, J. H. Bai and P. Han, Colloids Surf., A, 2018, 538, 460-466.

7 H. Demey, T. Vincent and E. Guibal, Chem. Eng. J., 2018, 332, 582-595.

8 D. Kavak, Desalin. Water Treat., 2013, 51, 1720-1726.

9 H. Yin and J. Zhu, Chem. Eng. J., 2016, 285, 112-120.

10 S. Heuss-Assbichler, M. John, D. Klapper, U. W. Blass and G. Kochetov, J. Environ. Manage., 2016, 181, 1-7.

11 J. Wang, W. T. Zhang, X. Y. Yue, Q. F. Yang, F. B. Liu, Y. R. Wang, D. H. Zhang, Z. H. Li and J. L. Wang, J. Mater. Chem. A, 2016, 4, 3893-3900.

12 C. W. Wong, J. P. Barford, G. Chen and G. McKay, J. Environ. Chem. Eng., 2014, 2, 698-707.

13 M. Benamor, Z. Bouariche, T. Belaid and M. T. Draa, Sep. Purif. Technol., 2008, 59, 74-84.

14 O. Arar, Desalin. Water Treat., 2014, 52, 3197-3205.

15 M. C. Revathi, A. Basha and M. Velan, Desalin. Water Treat., 2016, 57, 20350-20367.

16 M. Garmsiri and H. R. Mortaheb, Chem. Eng. J., 2015, 264, 241-250.

17 P. Otrembska and J. Gega, Sep. Sci. Technol., 2016, 51, 26752680.

18 J. Kheriji, D. Tabassi and B. Hamrouni, Water Sci. Technol., 2015, 72, 1206-1216.

19 H. Duan, S. Wang, X. Yang, X. Yuan, Q. Zhang, Z. Huang and H. Guo, Chem. Eng. Res. Des., 2017, 117, 460-471.

20 A. Labidi, A. M. Salaberria, S. C. M. Fernandes, J. Labidi and M. Abderrabba, J. Taiwan Inst. Chem. Eng., 2016, 65, 140-148.

21 M. Mushtaq, H. N. Bhatti, M. Iqbal and S. Noreen, J. Environ. Manage., 2016, 176, 21-33.

22 Z. S. Chen, G. J. Lee and J. C. Liu, Chemosphere, 2000, 41, 235-242.

23 W. Y. Shi, H. Li, S. Du, K. B. Wang and H. B. Shao, Appl. Clay Sci., 2013, 85, 103-108.

24 C. Y. Cao, C. H. Liang, Y. Yin and L. Y. Du, J. Hazard. Mater., 2017, 329, 222-229.

25 M. J. Wu, J. Zhang, Y. Q. Peng, J. Z. Zhou, X. X. Ruan, J. Y. Liu, Q. Liu, Y. F. Xi, R. Frost and G. G. Qian, Microporous Mesoporous Mater., 2017, 242, 182-189.

26 R. Krebs, S. K. Gupta, G. Furrer and R. Schulin, Water, Air, Soil Pollut., 1999, 115, 465-479.

27 E. Lombi, F. J. Zhao, G. Zhang, B. Sun, W. Fitz, H. Zhang and S. P. McGrath, Environ. Pollut., 2002, 118, 435-443.

28 C. Keller, M. Marchetti, L. Rossi and N. Lugon-Moulin, Plant Soil, 2005, 276, 69-84.

29 Y. Du, F. Lian and L. Y. Zhu, Environ. Pollut., 2011, 159, 17631768.

30 C. A. Flemming, F. G. Ferris, T. J. Bevaridge and G. W. Bailey, Appl. Environ. Microbiol., 1990, 56, 3191-3203. 
31 R. Celis, M. C. Hermosin and J. Cornejo, Environ. Sci. Technol., 2000, 34, 4593-4599.

32 H. Ni, Y. L. Li, R. P. Cui, Y. Lu and G. D. Yang, J. Environ. Eng., 2016, 6, 3077-3083.

33 S. Y. Hao, A. Verlotta, P. Aprea, F. Pepe, D. Caputo and W. D. Zhu, Microporous Mesoporous Mater., 2016, 236, 250259.

34 G. Li, B. D. Wang, Q. Sun, W. Q. Xu and Y. F. Han, Microporous Mesoporous Mater., 2017, 252, 105-115.
35 M. Liu, Y. Wang, L. Chen, Y. Zhang and Z. Lin, ACS Appl. Mater. Interfaces, 2015, 7, 7961-7969.

36 W. L. Wang, D. W. Zeng and Q. Y. Chen, Chem. Eng. Sci., 2013, 101, 120-129.

37 J. Wen, Z. L. Peng, Y. G. Liu, Y. Fang, G. M. Zeng and S. Y. Zhang, J. Soils Sediments, 2018, 18, 323-332.

38 C. Y. Cao, C. H. Liang, Y. Yin and L. Y. Du, J. Hazard. Mater., 2017, 329, 222-229. 